\title{
Is There A Relationship Between Visfatin Level and Type 2 Diabetes Mellitus In Obese And Non Obese Patients?
}

Eid M El-Shafey ${ }^{1 *}$, Gamal F El-Naggar ${ }^{1}$, Mohamed M Al-Bedewy ${ }^{2}$ and Hesham El-Sorogy

${ }^{1}$ Nephrology Division, Internal Medicine Department, Faculty of Medicine, Tanta University, Tanta, Egypt

${ }^{2}$ Internal Medicine Department, Faculty of Medicine, Tanta University, Tanta, Egypt

${ }^{3}$ Clinical Pathology Department, Faculty of Medicine, Tanta University, Tanta, Egypt

\begin{abstract}
Background: Visfatin is a newly discovered cytokine that is highly expressed in visceral fat with a direct relationship to type 2 diabetes mellitus (T2DM). The present study was conducted to demonstrate the relationship between plasma visfatin level and T2DM whether in obese or non obese patients.
\end{abstract}

Subjects and methods: This prospective study was carried out on 74 subjects divided into 4 groups. Group I: Twenty obese non diabetic patients, Group II: Twenty obese diabetic patients, Group III: Twenty non obese diabetic patients and Group IV: Fourteen age and gender matched apparently healthy subjects to serve as controls. All patients and controls were subjected to full history taking, complete clinical examination, routine laboratory investigations, fasting serum insulin, homeostasis model assessment of insulin resistance $\left(\mathrm{HOMA}_{\mathbb{R}}\right)$ and serum visfatin level.

Results: Serum visfatin level was significantly increased in the obese subjects and in the diabetics with the highest rise in the obese diabetics suggesting that serum visfatin level has a link between obesity and T2DM. Also, there was a significant positive correlation between serum visfatin level and body mass index (BMI), serum insulin \& $\mathrm{HOMA}_{\mathbb{R}}$.

Conclusion: There may be a possible role of visfatin in the Pathophysiology of insulin resistance, T2DM and obesity.

Keywords: Visfatin; Type 2 diabetes mellitus; Obesity

\section{Introduction}

The incidence of Type 2 diabetes mellitus (T2DM) continues to increase dramatically in most parts of the world, and the ways to prevent or cure the disorder are limited despite enormous research efforts [1]. Excess adiposity is the most important risk in the development of insulin resistance and T2DM [2]. Adipose tissue produces several proteins (adipocytokines) such as leptin, adiponectin, resistin, TNFa, IL-6 and visfatin that modulate insulin sensitivity and appear to play an important role in the pathogenesis of insulin resistance, diabetes, dyslipidemia, inflammation, and atherosclerosis [3]. Visfatin is a newly discovered adipocyte hormone with a direct relationship to T2DM. This hormone is found in the cytoplasm as well as the nucleus of cells and has been identified in many tissues and organs including the brain, kidney, lung, spleen and testis but preferentially expressed in visceral adipose tissue [4]. Visfatin binds to the insulin receptor at a site distinct from that of insulin and causes hypoglycemia by reducing glucose release from liver cells and stimulating glucose utilization in adipocytes and myocytes. Visfatin is upregulated by hypoxia, inflammation and hyperglycemia and down regulated by insulin, somatostatin and statins [5]. Visfatin seems to modulate insulin sensitivity and appear to play an important role in the pathogenesis of insulin resistance, diabetes, dyslipidemia, inflammation, and atherosclerosis [2]. Moreover, there has been increasing evidence of the association between insulin resistance and subclinical inflammation involving cytokines derived from adipose tissue or adipocytokines. Knowledge of how these adipose tissue-derived factors influence metabolic and cardiovascular disease has recently expanded, and growing evidence implicates adipocytederived factors as major regulator of insulin resistance. Interestingly, visfatin and not adiponectin or resistin levels were associated with T2DM [2]. The aim of the present study is to explore the relation of serum visfatin and T2DM whether in obese or non obese patients.

\section{Subjects and Methods}

\section{Subjects}

From May 2010 to June 2011, 74 subjects who consecutively visited the outpatient Department of Tanta University Hospitals were studied. The study subjects were divided into the following groups: Group I (obese non diabetics): Twenty obese non diabetic patients ( 8 males and 12 females; mean age of $37.24 \pm 8.12 \mathrm{yr}$ ), Group II (obese diabetics): Twenty obese diabetic patients ( 7 males and 13 females; mean age of $38.46 \pm 10.90$ ), Group III ( Non obese diabetics): Twenty non obese diabetic patients ( 9 males and 11 females; mean age of $39 \pm$ 5 yr), Group IV (controls): Fourteen non obese non diabetic subjects (7 males and 7 females; mean age of $35.32 \pm 7.31 \mathrm{yr}$ ). Obese patients were chosen according to body mass index (BMI) $\left(>30 \mathrm{~kg} / \mathrm{m}^{2}\right)$. The diagnosis of T2DM was based on the World Health Organization criteria [6]. Patients presenting with symptoms suggestive of type 1 diabetes, defined as diabetic ketoacidosis, or continuous requirement of insulin within $1 \mathrm{yr}$ of diagnosis, were excluded [7]. Patients who have had a diagnosis of urinary tract infection, urolithiasis, macrovascular diseases, congestive heart failure, overt proteinuria, liver cirrhosis, or other known major diseases were excluded. This study was approved

*Corresponding author: Eid M El-Shafey, Faculty of Medicine, Internal Medicine Department, Nephrology Division, Tanta University, Tanta, Egypt, Tel: 0096524580217; Fax: 0096524567427; E-mail: shafey70@yahoo.com

Received May 29, 2012; Accepted July 07, 2012; Published July 13, 2012

Citation: El-Shafey EM, El-Naggar GF, Al-Bedewy MM, El-Sorogy H (2012) Is There A Relationship Between Visfatin Level And Type 2 Diabetes Mellitus In Obese And Non Obese Patients? J Diabetes Metab S11:001. doi:10.4172/21556156.S11-001

Copyright: (C) 2012 El-Shafey EM, et al. This is an open-access article distributed under the terms of the Creative Commons Attribution License, which permits unrestricted use, distribution, and reproduction in any medium, provided the original author and source are credited. 
by the human research ethics committee of the hospital, and informed consent was obtained from each patient.

\section{Methods}

All patients and controls underwent full history taking, complete physical examination and routine biochemical analyses of blood (fasting and postprandial blood glucose level by glucose oxidase method, complete lipid profile by commercial enzymatic methods, including serum total cholesterol, serum triglycerides and serum HDL-cholesterol which was determined after precipitation of LDL and VLDL with dextran sulphate and $\mathrm{MgCl}_{2}$ ). LDL-cholesterol was calculated according to Friedewald formula: LDL-cholesterol equals total cholesterol minus [HDL-cholesterol plus total triglyceride/2.2] in millimole per liter in subjects with total triglyceride level $<4.5 \mathrm{mmol} / \mathrm{L}$, the homeostasis model assessment of insulin resistance $\left(\mathrm{HOMA}_{\mathrm{IR}}\right)$ was calculated from fasting insulin and glucose by the following equation: $\mathrm{HOMA}_{\mathrm{IR}}=$ insulin (microunits per milliliter $) \times$ glucose $(\mathrm{mmol} /$ liter $) / 22.5$ [8]. Fasting serum insulin [9] and visfatin levels [10] were determined by commercial enzyme immunoassay kits. For all subjects, $10 \mathrm{ml}$ of peripheral venous blood was collected in clean vacutainer tube and serum was separated and divided into 2 ependorff tubes, one tube for measurement of routine tests and the other tube was stored at $-70^{\circ} \mathrm{C}$ for further measurement of serum visfatin and insulin levels.

\section{Principle of determination of serum visfatin level by RayBio Visfatin Enzyme Immunoassay (EIA) Kit, (@2008 RayBiotech, Inc. 3607 Parkway Lane, Suite 200 Norcross, GA 30092, USA)}

The RayBio ${ }^{\circ}$ visfatin Enzyme Immunoassay (EIA) Kit is an in vitro quantitative assay for detecting visfatin peptide based on the principle of Competitive Enzyme Immunoassay. The microplate in the kit is precoated with anti-rabbit secondary antibody. After a blocking step and incubation of the plate with anti-visfatin antibody, both biotinylated visfatin peptide and peptide standard or targeted peptide in samples interacts competitively with the visfatin antibody. Uncompeted (bound) biotinylated visfatin peptide then interacts with Streptavidinhorseradish peroxidase (SAHRP), which catalyzes a color development reaction. The intensity of colorimetric signal is directly proportional to the amount of biotinylated peptide-SA-HRP complex and inversely proportional to the amount of visfatin peptide in the standard or samples. This is due to the competitive binding to visfatin antibody between biotinylated visfatin peptide and peptides in standard or samples. A standard curve of known concentration of visfatin peptide can be established and the concentration of visfatin peptide in the samples can be calculated accordingly.

\section{Statistical Analysis}

The data were expressed as mean \pm SD. All of the statistical analyses were performed using a standard statistical package (SPSS for Windows, release 16.0; SPSS Inc., Chicago, IL, USA). Between groups comparisons were made with One-Way ANOVA test, or Person Chi-Square test as appropriate. The association of visfatin with other variables was examined by Person correlation coefficient method. All of the statistical analyses were two sided, and $\mathrm{P}<0.05$ was considered statistically significant.

\section{Results}

The demographic, clinical and biochemical characteristics of our subjects are shown in Table 1. A total of 60 patients and fourteen age and sex-matched apparently healthy volunteers were studied. Group I and II patients had significantly higher BMI than that of control subjects $(\mathrm{p}<0.01)$. BMI showed significant increase in Group II patients compared with group I patients $(\mathrm{p}<0.05)$, while insignificant difference in group III patients compared with control subjects $(\mathrm{p}>0.05)$. The mean fasting serum visfatin levels were found to be significantly elevated in obese non diabetic patients and obese diabetics compared with control subjects $(34.61 \pm 4.68 ; 42.55 \pm 7.16$ vs. $17.4 \pm 3.44 \mathrm{ng} /$ $\mathrm{ml}, \mathrm{P}<0.001$, respectively), and in obese diabetic patients compared with obese non diabetics $(42.55 \pm 7.16$ vs. $34.61 \pm 4.68 \mathrm{ng} / \mathrm{ml}, \mathrm{P}<0.01)$ Meanwhile, there was no significant difference in serum visfatin levels in non obese diabetic patients compared with control subjects $(23.5$ \pm 5 vs. $17.4 \pm 3.44 \mathrm{ng} / \mathrm{ml}, \mathrm{P}>0.05$ ) (Figure 1 ). Thirty-eight diabetic patients were treated with oral hypoglycaemic agents alone and two

\begin{tabular}{|c|c|c|c|c|c|c|c|c|c|}
\hline Parameter & $\begin{array}{l}\text { Obese non-dia- } \\
\text { betic patients }\end{array}$ & $\begin{array}{l}\text { Obese diabetic } \\
\text { patients }\end{array}$ & $\begin{array}{l}\text { Non obese dia- } \\
\text { betic patients }\end{array}$ & Controls & P-value & $P_{1}$ & $\mathbf{P}_{2}$ & $\mathbf{P}_{3}$ & $\mathbf{P}_{4}$ \\
\hline $\begin{array}{l}\text { Age } \\
(\mathrm{yr}, \text { mean } \pm \mathrm{SD})\end{array}$ & $37.24 \pm 8.12$ & $38.46 \pm 10.90$ & $39 \pm 5$ & $35.32 \pm 7.31$ & $>0.05$ & $>0.05$ & $>0.05$ & $>0.05$ & $>0.05$ \\
\hline Body mass index $\left(\mathrm{kg} / \mathrm{m}^{2}\right)$ & $32.17 \pm 2.50$ & $35.98 \pm 2.14$ & $21 \pm 2$ & $22.49 \pm 1.21$ & $<0.05^{*}$ & $<0.05^{*}$ & $<0.01^{*}$ & $<0.01^{*}$ & $>0.05$ \\
\hline $\begin{array}{l}\text { Gender } \\
\text { Male }(\mathrm{n}, \%) \\
\text { Female }(\mathrm{n}, \%)\end{array}$ & $\begin{array}{l}8(40) \\
12(60)\end{array}$ & $\begin{array}{l}7(35) \\
13(65)\end{array}$ & $\begin{array}{l}9(45) \\
11(55)\end{array}$ & $\begin{array}{l}7(50) \\
7(50)\end{array}$ & $>0.05$ & & & & \\
\hline $\begin{array}{l}\text { Triglyceride } \\
(\mathrm{mmol} / \mathrm{L})\end{array}$ & $4.50 \pm 0.18$ & $4.91 \pm 0.40$ & $1.64 \pm 0.12$ & $1.51 \pm 0.28$ & $<0.01^{*}$ & $<0.001^{*}$ & $<0.001^{*}$ & $<0.001^{*}$ & $>0.05$ \\
\hline $\begin{array}{l}\text { Total cholesterol } \\
(\mathrm{mmol} / \mathrm{L})\end{array}$ & $8.69 \pm 0.53$ & $9.33 \pm 0.38$ & $5.59 \pm 0.59$ & $4.93 \pm 0.78$ & $<0.01^{*}$ & $<0.01^{*}$ & $<0.001^{*}$ & $<0.001^{*}$ & $>0.05$ \\
\hline $\begin{array}{l}\text { HDL- cholesterol } \\
(\mathrm{mmol} / \mathrm{L})\end{array}$ & $1.04 \pm 0.24$ & $0.78 \pm 0.21$ & $1.31 \pm 0.15$ & $1.43 \pm 0.23$ & $>0.05$ & $>0.05$ & $<0.001^{*}$ & $<0.001^{*}$ & $>0.05$ \\
\hline $\begin{array}{l}\text { LDL- cholesterol } \\
\text { (mmol/L) }\end{array}$ & $3.48 \pm 0.34$ & $3.59 \pm 0.29$ & $3.24 \pm 0.28$ & $3.07 \pm 0.40$ & $>0.05$ & $>0.05$ & $<0.01^{*}$ & $<0.05^{*}$ & $>0.05$ \\
\hline Fasting Glucose (mmol/L) & $6.67 \pm 0.29$ & $12.78 \pm 1.67$ & $12.60 \pm 0.56$ & $5.29 \pm 0.23$ & $<0.01^{* *}$ & $<0.001^{* *}$ & $<0.001^{* *}$ & $<0.001^{* *}$ & $<0.001^{* *}$ \\
\hline $\begin{array}{l}\text { Serum Insulin } \\
(\mu \mathrm{IU} / \mathrm{ml})\end{array}$ & $15.87 \pm 1.0$ & $17.80 \pm 1.89$ & $16.01 \pm 1.10$ & $10.56 \pm 0.80$ & $<0.05^{*}$ & $<0.05^{*}$ & $<0.001^{* *}$ & $<0.001^{* *}$ & $<0.01^{* *}$ \\
\hline HOMA $_{\mathrm{IR}}$ & $4.71 \pm 0.51$ & $10.19 \pm 1.90$ & $8.98 \pm 0.96$ & $2.49 \pm 0.60$ & $<0.05^{\star}$ & $<0.001^{* *}$ & $<0.01^{* *}$ & $<0.001^{* *}$ & $<0.001^{* *}$ \\
\hline $\begin{array}{l}\text { Serum visfatin } \\
(\mathrm{ng} / \mathrm{ml})\end{array}$ & $34.61 \pm 4.68$ & $42.55 \pm 7.16$ & $23.5 \pm 5$ & $17.4 \pm 3.44$ & $<0.05^{*}$ & $<0.01^{* *}$ & $<0.001^{* *}$ & $<0.001^{* *}$ & $>0.05$ \\
\hline
\end{tabular}

*significant $(p<0.05) ;{ }^{* *}$ highly significant $(p<0.01)$; HDL: High Density Lipoproteins; LDL: Low Density Lipoproteins; P1: Comparison between obese non diabetic \& obese diabetic patients; P2: Comparison between obese non diabetics \& control subjects; P3: Comparison between obese diabetics \& control subjects ; P4: Comparison between non obese diabetics \& control subjects; $\mathrm{HOMA}_{\mathrm{IR}}$ : Homeostasis model assessment of insulin resistance

Table 1: Demographic, clinical and biochemical characteristics of the studied groups. 


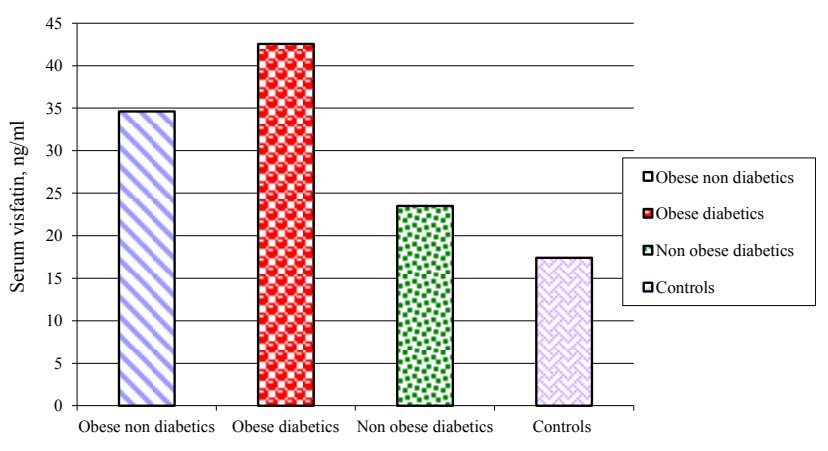

Figure 1: Serum visfatin levels among the studied groups.

\begin{tabular}{|l|l|l|}
\hline \multirow{2}{*}{ Parameter } & \multicolumn{2}{|c|}{ Visfatin } \\
\cline { 2 - 3 } & r. & p. value \\
\hline Body mass index $\left(\mathrm{kg} / \mathrm{m}^{2}\right)$ & 0.649 & $0.002^{*}$ \\
\hline HOMA $_{\mathrm{IR}}$ & 0.364 & $0.034^{*}$ \\
\hline Serum insulin $(\mu \mathrm{IU} / \mathrm{ml})$ & 0.332 & $0.049^{*}$ \\
\hline
\end{tabular}

*significant $(p<0.05)$; HOMA : Homeostasis model assessment of insulin resistance

Table 2: Correlation between serum visfatin and $\mathrm{BMI}, \mathrm{HOMA}_{\mathrm{IR}}$ and fasting serum insulin in the obese diabetic group.

cases with combined insulin and oral hypoglycemic agents. Among patients on treatment with oral hypoglycemic agents, fifteen cases were on sulfonylurea alone, five on metformin alone, fifteen on sulfonylurea and metformin, and four on sulfonylurea and thiazolidinediones. The mean serum level of visfatin in subjects receiving insulin treatment did not differ from that of patients receiving oral hypoglycemic agents. The mean serum visfatin levels of diabetic subjects on different oral hypoglycemics did not show any difference among the groups, yet the number of subjects is too small to draw any conclusion.

Serum visfatin concentration was positively associated with BMI $(\mathrm{r}=0.649, \mathrm{p}=0.002)$, serum insulin level $(\mathrm{r}=0.332, \mathrm{p}=0.049) \& \mathrm{HOMA}_{\mathrm{IR}}$ $(\mathrm{r}=0.364, \mathrm{p}=0.034)$, in obese diabetic patients (Table 2; Figure 2). It is known that overweight/obese patients have an abundance of adipose tissue, which is distributed mainly in the central trunk as visceral fat. Our results support the hypothesis that circulating visfatin concentrations are largely determined by body weight/obesity, probably mainly by visceral adipose tissue, implying that increased adipose tissue is the one of the sources of serum visfatin.

As shown in Table 1, both serum total cholesterol and triglyceride levels were significantly higher in Group I \& II patients compared with control subjects $(\mathrm{P}<0.001)$, and in Group II patients compared with Group I patients $(\mathrm{P}<0.01)$. Meanwhile, there was no significant difference in group III patients compared with control subjects $(\mathrm{P}>0.05)$. Both HDL-cholesterol and LDL-cholesterol levels were significantly higher in Group I \& II patients compared with control subjects $(\mathrm{P}<0.001)$, Meanwhile, there was no significant difference in Group II patients compared with Group I patients and in Group III patients compared with control subjects $(\mathrm{P}>0.05)$. Fasting blood glucose and serum insulin levels were significantly higher in Group I, II \& III patients compared with control subjects $(\mathrm{P}<0.001 ; \mathrm{P}<0.001$, $\mathrm{P}<0.001, \mathrm{P}<0.01$, respectively), and in Group II patients compared with Group I patients $(\mathrm{P}<0.001 ; \mathrm{P}<0.05$, respectively). Group I, II \& III patients showed significant increase in $\mathrm{HOMA}_{\mathrm{IR}}$ compared with control subjects $(\mathrm{P}<0.01, \mathrm{P}<0.001, \mathrm{P}<0.001$, respectively). Also, there was significant increase in $\mathrm{HOMA}_{\mathrm{IR}}$ in group II patients compared with group I patients $(\mathrm{P}<0.001)$.

\section{Discussion}

The biological mechanisms involving visfatin in the pathogenesis of T2DM are not well understood. Visfatin as an adipokine has recently been identified and named as such because of its much greater expression in visceral fat than in subcutaneous adipose tissue. In keeping with its insulin-mimetic effects, visfatin was as effective as insulin in reducing hyperglycemia in insulin-deficient diabetic mice. Visfatin was also bound to and activated insulin receptors, causing receptor phosphorylation and the activation of the downstream signaling molecules [2]. In the present study, total cholesterol, and serum triglyceride levels showed significant increase in obese non-diabetic \& obese diabetic patients compared with control subjects. There was significant increase in total cholesterol and serum triglyceride levels, but not serum HDL-cholesterol and LDL-cholesterol levels in obese diabetic patients compared with obese non-diabetic patients. These results are in agreement with Derosa et al [11] who demonstrated significant abnormal changes as regard total cholesterol, LDL-cholesterol, HDL-cholesterol and serum triglyceride in obese patients. As regarding serum insulin and $\mathrm{HOMA}_{\mathrm{IR}}$, there was significant increase in obese non-diabetic, obese diabetic \& non-obese diabetic patients compared with control subjects. Also, they showed a significant rise in obese diabetic patients compared with obese nondiabetic patients. These results are in accordance with Magni et al. [12] who reported that patients in the overweight group had higher levels of insulin and insulin resistance compared with the controls. Hyperinsulinemia and increased insulin resistance, as demonstrated by $\mathrm{HOMA}_{\mathrm{IR}}$ index, in persons with an excessive amount of adipose tissue were confirmed in numerous observations. Also, Guagnano et al. [13] reported that hyperinsulinemia and lowered concentration of HDL-cholesterol co-existing with obesity. In addition, Sakamoto et al. [14] demonstrated that BMI, fasting plasma glucose, total cholesterol, serum triglycerides fasting insulin, and $\mathrm{HOMA}_{\mathrm{IR}}$ were significantly higher in the diabetic group compared with the nondiabetic group. It is important to mention that metabolic syndrome consists of the combined presentation of multiple cardiovascular risk factors, such as central obesity, elevated triglycerides, decreased highdensity lipoprotein cholesterol, hypertension and impaired glucose metabolism. For a diagnosis of metabolic syndrome, patients must fulfill at least three of these five criteria. In this study we demonstrated that visfatin levels were significantly elevated in obese patients and that visfatin is associated with abdominal obesity. Our results showed an increased visfatin concentration in T2DM and this may also support the hypothesis that visfatin is associated with impaired glucose metabolism. Furthermore, we found a significant positive correlation between visfatin concentration and BMI, serum insulin level \& $\mathrm{HOMA}_{\mathrm{IR}}$ in obese diabetic patients, insulin resistance is known as the central core of metabolic syndrome. On the basis of these results, these may be possible explanations for the significance of visfatin in diagnosing metabolic syndrome. Choi et al. showed that the level of visfatin was higher in obese participants as compared with that in non-obese participants among Korean women [15]. They also showed that plasma visfatin can be lowered after body weight reduction by an exercise program, and this result also held for non-obese subjects [15]. Soon after, Araki et al. [16] reported that the plasma visfatin level was higher in the obese patients than in the controls, the visfatin correlated significantly with body weight, triglycerides (TG), insulin, and the homeostasis model assessment for insulin resistance $\left(\mathrm{HOMA}_{\mathrm{IR}}\right)$ suggested that plasma visfatin level is a specific marker for visceral fat accumulation and for insulin resistance in obese. Another studies 

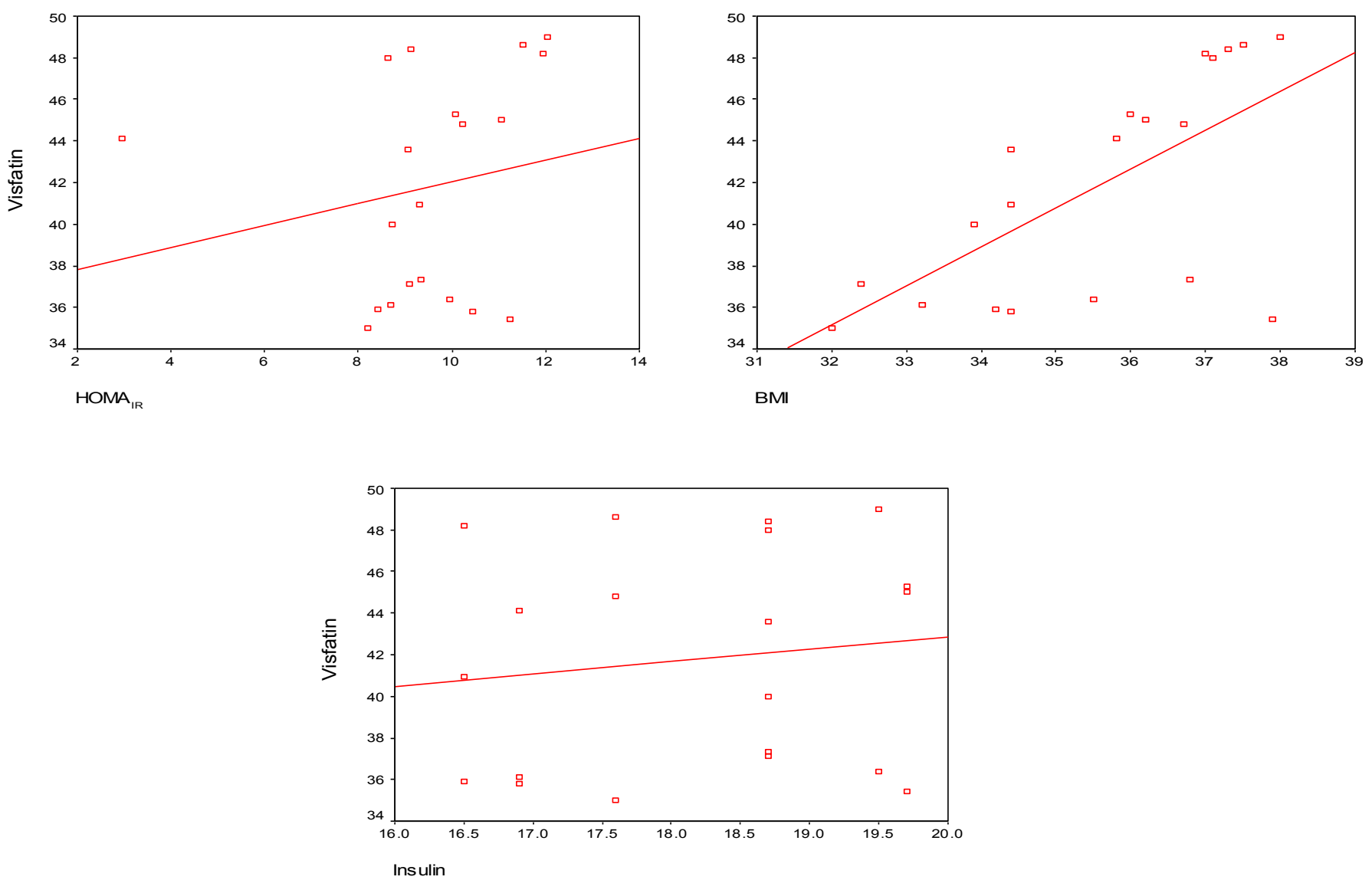

Figure 2: Correlation between serum visfatin level, BMI, $\mathrm{HOMA}_{\mathrm{IR}}$ \& serum insulin level in obese diabetic patients.

reported that the mean serum visfatin level of subjects with metabolic syndrome was significantly higher than the mean level of subjects without metabolic syndrome $(\mathrm{p}<0.01)$. As the number of components of metabolic syndrome increased, the concentration of serum visfatin also increased. Visfatin concentration was positively correlated with fasting glucose level, fasting insulin level, $\mathrm{HOMA}_{\mathrm{IR}}$, total cholesterol level and triglyceride level [17-21]. Chang YH et al. [22] found in their meta-analysis study that plasma visfatin is significantly increased in subjects diagnosed with overweight/obesity, T2DM, metabolic syndrome and cardiovascular disease. Furthermore, the results indicate that plasma visfatin is related to insulin resistance, as assessed by the homeostasis model assessment. Also, their meta-analysis confirmed an interaction between visfatin and glucose homeostasis, and suggests that this phenomenon is not prejudiced by the extent of overweight/ obesity. On the contrary, other studies reported that obese subjects had significantly lower visfatin levels compared to subjects with normal body weight $[23,24]$. On the other hand, Kamińska et al. have not reported differences in visfatin levels between obese and lean subjects [19]. In a study by Lopez-Bermejo [25], patients with longer-standing T2DM had visfatin levels higher than in non-diabetics. Visfatin levels increased with progressive pancreatic beta-cell dysfunction suggesting that the increase in the level of visfatin is a compensatory mechanism that develops in endogenous insulin deficit in patients with longerstanding type 2 diabetes mellitus. It is becoming clear that adipose tissue is not simply a reservoir for excess nutrients but an active and dynamic organ capable of expressing several cytokines and fat-derived peptides [2]. There has been increasing evidence of the association between insulin resistance and subclinical inflammation involving cytokines derived from adipose tissue or adipocytokines [1,3,26,27]. Knowledge of how these adipose tissue-derived factors influence metabolic and cardiovascular disease has recently expanded, and growing evidence implicates adipocyte-derived factors as major regulator of insulin resistance $[27,28]$. Our study has a limitation of being done on a small sample sizes, so further studies on a larger scale of subjects are recommended to confirm the link between visfatin level and diagnosis of the potentially diabetics early and metabolic syndrome.

\section{Conclusion}

Our study revealed elevated circulating serum visfatin in type 2 diabetics and obese subjects and these results were supported by a significant association between visfatin and insulin resistance, which indicates that visfatin may play a role in the pathophysiology of insulin resistance, T2DM and obesity.

\section{References}

1. Arner P (2006) Visfatin--a true or false trail to type 2 Diabetes Mellitus. J Clin Endocrinol Metab 91: 28-30.

2. Chen MP, Chung FM, Chang DM, Tsai JC, Huang HF, et al. (2006) Elevated plasma level of visfatin/pre-B cell colony-enhancing factor in patients with type 2 diabetes mellitus. J Clin Endocrinol Metab 91: 295-299. 
Citation: El-Shafey EM, El-Naggar GF, Al-Bedewy MM, El-Sorogy H (2012) Is There A Relationship Between Visfatin Level And Type 2 Diabetes Mellitus In Obese And Non Obese Patients? J Diabetes Metab S11:001. doi:10.4172/2155-6156.S11-001

Page 5 of 5

3. Fantuzzi G (2005) Adipose tissue, adipokines, and inflammation. J Allergy Clin Immunol 115: 911-919.

4. Filippatos TD, Randeva HS, Derdemezis CS, Elisaf MS, Mikhailidis DP (2010) Visfatin/PBEF and Atherosclerosis-Related Diseases. Curr Vasc Pharmacol 8 $12-28$.

5. Adeghate E (2008) Visfatin: structure, function and relation to diabetes mellitus and other dysfunctions. Curr Med Chem 15: 1851-1862.

6. Alberti KG, Zimmet PZ (1998) Definition, diagnosis and classification of diabetes mellitus and its complications. Part 1: Diagnosis and classification of diabetes mellitus, provisional report of a WHO consultation. Diabet Med 15: 539-553

7. Laakso M, Pyorala K (1985) Age of onset and type of diabetes. Diabetes Care 8: 114-117.

8. Matthews DR, Hosker JP, Rudenski AS, Naylor BA, Treacher DF, et al. (1985) Homeostasis model assessment: insulin resistance and beta-cell function from fasting plasma glucose and insulin concentrations in man. Diabetologia 28 : 412-419.

9. Temple R, Clark PM, Hales CN (1992) Measurement of insulin secretion in type 2 diabetes: problems and pitfalls. Diabet Med 9: 503-512.

10. Kim MK, Lee JH, Kim H, Park SJ, Kim SH, et al. (2006) Crystal structure of visfatin pre B-cell colony-enhancing factor1/nicotinamide phosphoribosyltransferase, free and in complex with the anti cancer agent FK-866. J Mol Biol 362: 66-77.

11. Derosa G, Maffioli P, Salvadeo SA, Ferrari I, Gravina A, et al. (2010) Sibutramine and $\mathrm{L}$-carnitine compared to sibutramine alone on insulin resistance in diabetic patients. Intern Med 49: 1717-1725

12. Magni P, Liuzzi A, Ruscica M, Dozio E, Ferrario S, et al. (2005) Free and bound plasma leptin in normal weight and obese men and women: relationship with body composition, resting energy expenditure, insulin-sensitivity, lipid profile and macronutrient preference. Clin Endocrinol 62: 189-196.

13. Sakamoto A, Ishizaka Y, Toda E, Nagai R, Koike K, et al. (2010) Impact of changes in obesity parameters on glucose metabolism and insulin resistance over a one-year period. J Atheroscler Thromb 17: 1246-1255

14. Guagnano MT, Romano M, Falco A, Nutini M, Marinopiccoli M, et al. (2003) Leptin increase is associated with markers of the hemostatic system in obese healthy women. J Thromb Haemost 1: 2330-2334.

15. Choi KM, Kim JH, Cho GJ, Baik SH, Park HS, et al. (2007) Effect of exercise training on plasma visfatin and eotaxin levels. Eur J Endocrinol 157: 437-442.
16. Araki S, Dobashi K, Kubo K, Kawagoe R, Yamamoto Y, et al. (2008) Plasma visfatin concentration as a surrogate marker for visceral fat accumulation in obese children. Obesity (Silver Spring) 16: 384-388.

17. Kim JH, Kim SH, Im JA, Lee DC (2010) The relationship between visfatin and metabolic syndrome in postmenopausal women. Maturitas 67: 67-71.

18. Pfutzner A, Hanefeld M, Lübben G, Weber MM, Karagiannis E, et al. (2007) Visfatin: a putative biomarker for metabolic syndrome is not influenced by pioglitazone or simvastatin treatment in nondiabetic patients at cardiovascular risk -- results from the PIOSTAT study. Horm Metab Res 39: 764-768.

19. Kaminska A, Kopczynska E, Bronisz A, Zmudzinska M, Bielinski M, et al. (2010) An evaluation of visfatin levels in obese subjects. Endokrynol Pol 61: 169-173.

20. Haider DG, Schindler K, Schaller G, Prager G, Wolzt M, et al. (2006) Increased plasma visfatin concentrations in morbidly obese subjects are reduced after gastric banding. J Clin Endocrinol Metab 91: 1578-1581.

21. García-Fuentes E, García-Almeida JM, García-Arnés J, García-Serrano S, RivasMarín J, et al. (2007) Plasma visfatin concentrations in severely obese subjects are increased after intestinal bypass. Obesity (Silver Spring) 15: 2391-2395.

22. Chang YH, Chang DM, Lin KC, Shin SJ, Lee YJ (2011) Visfatin in overweight/ obesity, type 2 diabetes mellitus, insulin resistance, metabolic syndrome and cardiovascular diseases: a meta-analysis and systemic review. Diabetes Metab Res Rev 27: 515-527.

23. Pagano C, Pilon C, Olivieri M, Mason P, Fabris R, et al. (2006) Reduced plasma visfatin/pre-B cell colony -enhancing factor in obesity is not related to insulin resistance in humans. J Clin Endocrinol Metab 91: 3165-3170.

24. Jian WX, Luo TH, Gu YY, Zhang HL, Zheng S et al. (2006) The visfatin gene is associated with glucose and lipid metabolism in a Chinese population. Diabe Med 23: 967-973.

25. López-Bermejo $A$, Chico-Julià $B$, Fernàndez-Balsells $M$, Recasens $M$, Esteve $E$ et al. (2006) Serum visfatin increases with progressive beta-cell deterioration Diabetes 55: 2871-2875.

26. Kershaw EE, Flier JS (2004) Adipose tissue as an endocrine organ. J Clin Endocrinol Metab 89: 2548-2556.

27. Sharma AM, Chetty VT (2005) Obesity, hypertension and insulin resistance Acta Diabetol 42: S3-S8.

28. Fasshauer M, Paschke R (2003) Regulation of adipocytokines and insulin resistance. Diabetologia 46: 1594-1603. 